\title{
Computational Studies on 3-Aza-Cope Rearrangements: Protonation- Induced Switch of Mechanism in the Reaction of Vinylpropargylamine
}

\author{
Rainer F. Winter ${ }^{[\mathrm{b}]}$ and Guntram Rauhut*[a]
}

\begin{abstract}
The 3-aza-Cope rearrangements of 3-azoniahexa-1,5-diene (1), 3-azoniahex-1-ene-5-yne (3), and 3-azahex-1-ene-5-yne (5) were investigated up to the coupled-cluster level, $\operatorname{CCSD}(\mathrm{T})$, by using a valence triple- $\zeta$ basis set. Activation barriers and geometrical parameters of the transition states are provided. Conformational studies were performed for all reactants and products of the reactions. Solvent effects were estimated from self-consistent reaction field calculations. In contrast to the other two species, the Cope rearrangement of $\mathbf{5}$ was found to proceed by a stepwise mechanism.
\end{abstract}

\section{Introduction}

Cope-type rearrangements constitute a highly efficient means for carbon-carbon bond formation. They offer high regioand stereocontrol, which renders these processes especially valuable in natural product synthesis. This is especially true for the Claisen- $(X=O)$ and the 3-aza-Cope $(X=N R$, see Scheme 1) variants. The products of these [3,3]-sigmatropic processes are $\gamma, \delta$-unsaturated aldehydes (for $\mathrm{X}=\mathrm{NR}$ after

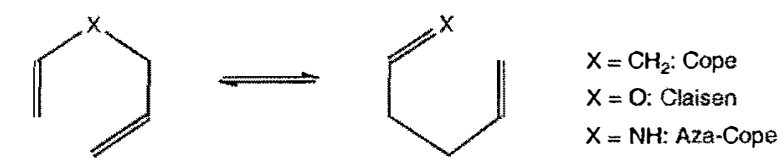

Scheme 1. Classification of Cope rearrangements.

subsequent hydrolysis of the initially formed imines), which themselves are valuable synthons owing to their intrinsically different reactivities inherent to the terminal functional groups.

The 3-aza-Cope rearrangement has some additional benefits over its oxo counterpart, most notably the higher degree

[a] Priv--Doz. Dr. G. Rauhut

Institus für Theoretische Chemie

Universität Stuttgart

Pfaffenwaldring 55, 70569 Stuttgart (Germany)

Fax: $(+49) 711-685-4442$

E-mail: rauhut@theochem.uni-stuttgart.de

[b] Dr. R. F. Winter

Institut für Anorganische Chemie

Universität Stuttgart

Pfaffenwaldring 55, 70569 Stuttgart (Germany)

E-mail: winter@iac.uni-stuttgart.de of $E / Z$ stereocontrol for the formation of the enamine as compared to vinyl ethers and the possibility to generate additional stereocenters by utilizing optically active allylamines, which are available from the chiral pool. Nevertheless, the 3-aza-Cope rearrangement has one severe drawback, namely the elevated temperatures of typically 170 $250^{\circ} \mathrm{C}$ required to induce the thermal rearrangement. ${ }^{(i-i)}$ This has initially crippled the synthetical utility of this otherwise highly attractive reaction. Another issue, namely the convenient synthesis of a wide variety of the respective functional-

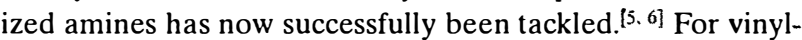
propargylamine derivatives even higher activation energies of at least $260^{\circ} \mathrm{C}$ are required..$^{1781}$ Here, the rearrangement furnishes allenic imines, or, after hydrolysis, the respective aldehydes. Besides being rather inconvenient for the experimentalist, the rather harsh conditions in many cases are incompatible with the presence of certain functional groups in the allyl- or propargylenamine precursor. This has led to considerable efforts directed at reducing the activation barriers. One practical method is to increase the electron density on the nitrogen atom through incorporation of more electron-rich ene functions. ${ }^{[4-11]}$ Deprotonation to allylamide enolates $^{[12]}$ or zwitterionic substrates ${ }^{[13]}$ also provides significantly decreased rearrangement temperatures. The most common approach, however, relies on rendering the nitrogen atom electron-poor. To these ends different strategies have been successfully applied ${ }^{[14-[6]}$ : 1) Bronsted acid catalysis $^{[5,6,17,18]}$ 2) Lewis acid catalysis ${ }^{[6,18-20]}$ 3) quaternization to the respective ammonium salts, ${ }^{[14,19,21-31]}$ and 4) combined Brønsted acid/Pd complex catalysis. ${ }^{[32]}$ One of us has recently reported that allylvinylammonium salts with a trans$\left\{\mathrm{Cl}(\mathrm{dppm})_{2} \mathrm{Ru}-\mathrm{C} \equiv \mathrm{C}\right\}$ moiety $(\mathrm{dppm}=$ bis(diphenylphosphino)methane) attached to the vinylic carbon adjacent to the 
nitrogen atom smoothly rearrange under ambient conditions to the corresponding iminium salts, which in this case are 3-butenyl-substituted aminoallenylidene complexes. ${ }^{[33]}$

In spite of the wealth of practical applications only few experimental data concerning the thermodynamic activation parameters of these transformations are known. For the aromatic (Claisen-type) uncatalyzed process $\Delta G^{\ddagger}$ values of some 40.6 to $48.5 \mathrm{kcalmol}^{-1}$ have been determined, while $\Delta H^{+}$ ranges from 34 to $40 \mathrm{kcalmol}^{-1}$, depending on the degree of methyl substitution on the allyl moiety. ${ }^{[1]}$ Strongly negative $\Delta S^{\ddagger}$ values are indicative of highly ordered transition states and support the concerted nature of this process. Jolidon et al. report values between -12 and -19 eu for $N$-allylanilines. ${ }^{[17]}$ The experimentally obtained $\Delta G^{\ddagger}$ and $\Delta H^{\ddagger}$ values of Jolidon and Hansen consistently drop by some $6-10\left(\Delta H^{\ddagger}\right)$ and $15-$ $17 \mathrm{kcalmol}^{-1}\left(\Delta G^{*}\right)$ under acidic conditions. For the neutral aliphatic systems investigated here and for those of Walters, ${ }^{[34]}$ theoretical calculations give considerably lower numbers that agree well with experimental evidence (vide infra). For the aliphatic processes experimentally derived activation energies have seemingly not been reported to date. In agreement with observations on other Cope-type rearrangements, solvent effects on the energy barriers appear to be rather small and this is even more true for the neutral processes. ${ }^{[17]}$

Since quantum-chemical calculations at low theoretical levels were not solely conclusive, there has been a long debate about the nature of the lowest pathway of the Cope rearrangement. ${ }^{[34-49]}$ The central question being discussed is whether the reaction proceeds via a concerted aromatic transition state or involves a biradical intermediate. Meanwhile, it has commonly been accepted that, irrespective of the constituent at the 3-position $\left(\mathrm{CH}_{2}, \mathrm{NH}, \mathrm{O}\right)$, the lowest energy pathway is concerted and proceeds via a chair-like aromatic structure. ${ }^{[38,42]}$ Of course, the question concerning the electronic nature also pertains to the stepwise mechanism. There are very few examples only where a stepwise mechanism has been observed, ${ }^{[4.37]}$ and the reactive intermediates involved in these mechanisms may be biradical in nature or not. Based on the evidence provided by the computational studies cited above we initially started our investigation by searching for concerted transition states at the restricted DFT level. However, for the last system investigated here, a stepwise mechanism was found to be most relevant and consequently particular effort was made to analyze the electronic nature of the molecular structures involved.

Quite recently, Walters reported a computational study of three 3-aza Cope rearrangements, namely of 3-azahexa-1,5diene, 3-azoniahexa-1,5-diene, and 3-azahexa-1,2,5-triene. ${ }^{[34]}$ At the MP4(SDTQ)/6-31G*//MP2/6-31G* level he obtained activation energies of $\Delta E^{\ddagger}=34.6,21.4$, and $17.7 \mathrm{kcal} \mathrm{mol}^{-1}$, respectively. These barriers apply to the chair-like transition states and the corresponding reactants. Unfortunately, the conformational flexibility of the hexadiene and hexatriene derivatives was not taken into account. In order to judge the importance of conformational aspects we used the rearrangement of 3-azoniahexa-1,5-diene (1) as a benchmark system and reinvestigated it using a slightly different methodology than Walters (see below). This reaction and the aza-Cope rearrangements of 3-azoniahex-1-ene-5-yne (3) and 3-azahex- 1-ene-5-yne (5) were studied up to the $\operatorname{CCSD}(\mathrm{T}) / \mathrm{cc}$ pVTZ $(f, p)$ level. To the best of our knowledge no computational or experimental results pertaining to the activation energies of these processes have been reported to date.

While most studies concerning the nature of the transition state do not pay respect to the conformational flexibility of the reactants and products, this particular aspect has been tackled in the context of improving molecular mechanics approaches. ${ }^{[50 .}{ }^{51]}$ These studies mainly focus on simple hydrocarbons rather than nitrogen-substituted compounds. Performing a conformational analysis for 1,5-hexadiene, Gung et al. ${ }^{\mid 50]}$ found that the lowest energy conformer does not exhibit $C_{\mathrm{i}}$ or $C_{2 \mathrm{~h}}$ symmetry as has been assumed by most authors studying transition states. ${ }^{[38.42]}$ In case of 1,5-hexadiene this effect may contribute up to only $5 \%$ of the activation energy, whereas it may amount by up to $25 \%$ for the aza compounds investigated here. Therefore, a conformational study of the reactants and products is an essential prerequisite for a proper determination of the activation barriers and reaction energies of aza-Cope rearrangements.

\section{Computational methods}

Potential-energy surfaces were scanned at the B3-LYP/cc-pVDZ ${ }^{\lfloor 2,53 !}$ level. All stationary points were verified by frequency calculations and a subsequent tracing of the intrinsic reaction coordinate (IRC). Single-point calculations at the B3-LYP/cc-pVTZ and LMP2/cc-pVTZ levels were used for the conformational studies of the reactants and products of each reaction. Local MP2 (LMP2) ${ }^{[5,45 \mid]}$ was used instead of its canonical counterpart, since it is computationally significantly more efficient. We used a threshold for the automatic virtual space selection of 0.985 , which is slightly larger than the recommended value of Boughton and Pulay. ${ }^{[5]]}$ These authors used basis sets of double- $\xi$ quality only and consequently a slightly higher value is more appropriate for the cc-pVTZ basis used here. The energy differences between the transition states and the conformers of the reactants and products lowest in energy were computed at the $\operatorname{CCSD}(T) / c c-p V T Z(f, p)$ level. In order to limit the computational effort $\mathrm{d}$ functions on hydrogen atoms had to be removed for these calculations. Rotational barriers between the conformers were not determined. since they are without relevance for the estimation of the reaction barrier. Zeropoint vibrational energy (ZPE) and thermal corrections to the coupled. cluster activation barrier were transferred from the corresponding DFT calculations. ZPEs were scaled by 0.963 in order to account for basis set deficiencies, anharmonicity, and missing-electron correlation contributions. ${ }^{[\$ 1}$ Additionally, multireference CASPT2 calculations based on internally contracted configurations ${ }^{[* 9]}$ were used for the investigation of the stepwise reaction mechanism of 3-azahex-1-ene-5-yne. On the basis of the occupation numbers of the natural orbitals, an active space comprising ten electrons in ten orbitals were used for determining the wavefunction at the underlying CASSCF level, that is, $\operatorname{CASSCF}(10,10)$. For the subsequent CASPT2/cc»pVTZ(f,p) calculations the same active space was chosen.

Solvent effects were estimated by a self-consistent reaction field approach (SCRF) with Tomasi's polarizable continuum model. ${ }^{[60.61]}$ To simulate an aqueous solution (as a prototype for a polar solvent) the dielectric constant was set to 78.4. Solvent effects were computed from single-point calculations only and, hence, geometry effects due to the chemical environment were not taken into account. Moreover, conformers that are isoenergetic in the gas phase may show slightly different free energies of solvation. This results from the construction of the cavity and must be considered an inherent numerical problem of the method. Since the effects are comparably small, we computed the solvation free energies for one of the enantiomers only. All calculations were performed using the Molpro $2000.4^{[6+1}$ and Gaussian $98^{[63]}$ suites of ab initio and DFT programs on standard dual-processor personal computers and an 8 proc. SUN Enterprise 3500 with $4 \mathrm{~GB}$ memory. 


\section{Results and Discussion}

The molecular rearrangement of 3-azoniahexa-1,5-diene: The rearrangement of 3-azoniahexa-1,5-diene (1) to 1-azoniahexa1,5-diene (2) is schematically shown in Scheme 2 . In principle $3^{3}=27$ conformers can be generated for 1 and for the resulting

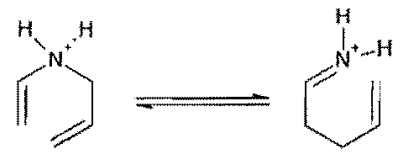

Scheme 2. The Cope rearrangement of 3-azonia-1,5-hexadiene.

product 2. Defining three dihedral angles $\alpha, \beta$ and $\gamma$ as shown in Figure 1, $\alpha$ and $\gamma$ may accept idealized values of 0 and \pm 120

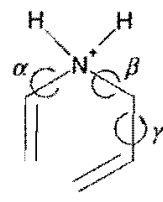

Figure 1. Definition of torsional angles in $\mathbf{1}$. degrees, while $\beta$ is limited to 180 and \pm 60 degrees. However, since most conformers exist as isoenergetic pairs of enantiomers the number of energetically unique conformers reduces to $14(\mathbf{a}-\mathbf{n})$. Note that, due to the introduction of the ammonium motif, there are more unique conformers than in the case of 1,5-hexadiene. ${ }^{[5 .}{ }^{51]}$ Although most computed dihedrals differ by less than 15 degrees from the idealized values, deviations can be as large as 30 degrees $(\mathbf{2} \mathbf{h})$. A list of all energetically distinct conformers of $\mathbf{1}$ is provided in Table 1 and the corresponding conformers of 2 are given in Table 2.

The relative B3-LYP-LMP2 energy differences for $\mathbf{1}$ amount only up to $0.8 \mathrm{kcalmol}^{-1}$, and, thus, the results of these methods closely resemble each other. In the gas phase, conformers $\mathbf{1} \mathbf{a}$ and $\mathbf{1 b}$ appear to be the most stable ones. Conformationally they differ by just a rotation of $\gamma$. Since the corresponding rotational barriers are usually in the range of 3

Table 1. Relative energies, ${ }^{[2]}$ solvation free energies, and dipole moments of energetically distinct conformers of 1 .

\begin{tabular}{|c|c|c|c|c|c|c|c|c|}
\hline & $\alpha^{[b]}$ & $\beta^{[\mathrm{b}]}$ & $\gamma^{(b)}$ & $\Delta E_{\mathrm{DIT}}^{[\mathrm{c}]}$ & $\Delta E_{\mathrm{LMY2}}$ [d] & 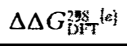 & $\Delta G_{\mathrm{DiT}}^{\text {soly }}$ & $\mu e^{[8]}$ \\
\hline $1 \mathbf{a}$ & 115.1 & 178.6 & -110.6 & 0.00 & 0.00 & 0.00 & -61.25 & 2.09 \\
\hline $1 \mathrm{~b}$ & 116.2 & 178.8 & 111.1 & 0.04 & 0.00 & 0.17 & -61.07 & 2.13 \\
\hline $1 \mathrm{c}$ & 117.1 & -69.2 & -111.9 & 0.71 & 0.32 & 0.94 & -63.03 & 3.08 \\
\hline Id & 119.5 & 69.0 & -115.8 & 0.91 & 0.52 & 1.08 & -63.32 & 3.13 \\
\hline le & 113.3 & 66.6 & 108.4 & 0.98 & 0.64 & 1.11 & -61.88 & 2.89 \\
\hline 1f & -114.2 & 72.1 & -113.2 & 1.28 & 0.77 & 1.19 & -63.56 & 3.25 \\
\hline $1 \mathrm{~g}$ & 116.1 & 178.7 & 0.4 & 1.78 & 1.63 & 1.86 & -63.27 & 1.81 \\
\hline $1 \mathrm{~h}$ & -0.4 & 180.0 & 110.2 & 1.84 & 1.59 & 2.19 & -60.37 & 2.31 \\
\hline $1 \mathbf{i}$ & -123.9 & -79.2 & -6.9 & 3.13 & 2.62 & 3.41 & -60.97 & 2.87 \\
\hline $1 \mathrm{j}$ & -14.3 & -73.1 & -111.7 & 3.32 & 2.72 & 3.65 & -62.99 & 3.23 \\
\hline $1 \mathrm{k}$ & 0.0 & 180.0 & 0.0 & 3.70 & 3.32 & 4.02 & -61.59 & 1.89 \\
\hline 11 & 137.0 & -76.7 & -4.1 & 4.05 & 3.44 & 4.09 & -64.70 & 3.20 \\
\hline $1 \mathrm{~m}$ & -9.4 & -71.9 & 129.0 & 4.11 & 3.49 & 4.23 & -64.55 & 3.59 \\
\hline ln & 7.2 & -76.7 & -4.1 & 4.97 & 4.18 & 5.39 & -65.86 & 3.26 \\
\hline
\end{tabular}

[a] All data refer to the cc-pVTZ basis set and are given in $\mathrm{kcalmol}^{-1}$. [b] The dihedrals $\alpha, \beta$, and $y$ specify the conformation of the structure. [c] Total B3-LYP/ccpVTZ energy of 1a: - 251.1031049 a.u. [d] Total LMP2/cc-pVTZ energy of 1a: -250.4387790 a.u. [e] Zero-point vibrational energies (scaled by 0.963 ) and thermal correction were transferred from B3-LYP/cc-pVDZ calculations. [f] Free energy of solvation, to be added to the total free energy of the molecule. [g] Dipole moments are provided in Debye.
Table 2. Relative energies, ${ }^{[a]}$ solvation free energies, and dipole moments of energetically distinct conformers of 2

\begin{tabular}{|c|c|c|c|c|c|c|c|c|}
\hline & $\alpha^{[b]}$ & $\beta^{(b)}$ & $\gamma^{[\mathrm{b}]}$ & $\Delta E_{\mathrm{DFT}} \mid \mathrm{fc|}$ & $\Delta E_{\mathrm{LMP}^{\prime}{ }^{(\mathrm{dl})}}$ & $\Delta \Delta G_{\mathrm{DFT}}^{288\}}$ & 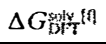 & $u^{[8]}$ \\
\hline $2 a$ & 15.3 & -58.5 & 127.4 & -14.68 & -14.20 & -14.33 & -59.76 & 4.86 \\
\hline $2 b$ & 17.8 & -65.7 & -12.8 & -12.91 & -12.52 & -12.57 & -61.63 & 4.82 \\
\hline $2 c$ & 133.7 & 64.2 & -118.0 & -12.67 & -11.67 & -12.94 & -64.70 & 6.88 \\
\hline $2 d$ & 112.9 & -66.0 & -108.1 & -12.03 & -11.16 & -12.54 & -62.78 & 6.27 \\
\hline $2 e$ & 119.1 & 178.3 & 116.6 & -12.02 & -10.61 & -12.44 & -65.39 & 7.83 \\
\hline $2 f$ & -1.0 & 178.9 & 116.7 & -11.96 & -10.76 & -12.34 & -61.57 & 7.54 \\
\hline $2 \mathrm{~g}$ & 113.4 & 178.1 & -115.8 & -11.75 & -10.38 & -12.25 & -64.68 & 7.95 \\
\hline $2 \mathrm{~h}$ & 149.4 & -62.5 & -7.6 & -11.44 & -10.47 & -11.47 & -66.28 & 5.94 \\
\hline $2 i$ & 122.7 & 57.3 & 102.9 & -11.31 & -10.13 & -11.73 & -63.16 & 7.10 \\
\hline $2 j$ & 0.0 & 180.0 & 0.0 & -11.23 & -10.07 & -11.38 & -62.64 & 7.45 \\
\hline $2 k$ & -131.3 & -68.0 & -15.7 & -11.18 & -10.24 & -11.30 & -59.55 & 6.73 \\
\hline 21 & 121.1 & 176.7 & -4.3 & -11.15 & -9.96 & -11.41 & -66.71 & 7.83 \\
\hline $2 m$ & 6.2 & 73.6 & 117.7 & -10.79 & -9.83 & -11.23 & -61.39 & 6.33 \\
\hline
\end{tabular}

[a] All data refer to the cc-pVTZ basis set. Energies are relative to la and are given in $\mathrm{kcalmol}^{-1}$. [b] The dihedrals $\alpha, \beta$, and $\gamma$ specify the conformation of the structure. [c] Total B3-LYP/cc-pVTZ energy of 2a: - 251.1264974 a.u. [d] Total LMP2/cc-pVTZ energy of 2a: - 250.4614033 a.u. [e] Zero-point vibrational energies (scaled by 0.963 ) and thermal correction were transferred from B3LYP/cc-pVDZ calculations. [f] Free energy of solvation, to be added to the total free energy of the molecule. $[\mathrm{g}]$ Dipole moments are provided in Debye.

to $6 \mathrm{kcalmol}^{-1},[50.51]$ there will be an even distribution between these two structures. Note that none of these two structures (1 $\mathbf{a}$ and $\mathbf{1} \mathbf{b})$ are the direct precursors of the Cope rearrangement. The precursor of the chair-like transition state is $\mathbf{1 f}$ and the precursor of the boat-like transition state is 1.c. According to the SCRF/B3-LYP calculations the most stable conformer in aqueous solution is indeed $\mathbf{1} \mathbf{f}$, but due to the comparably large inherent error of the SCRF approach and the small energetic differences between the conformers, this result must be considered with caution. Nevertheless, the values of $\Delta G^{\text {soiv }}$ demonstrate that solvation effects are of the same magnitude as the conformational energy differences, and, consequently, the conformational distribution strongly depends on the solvent. According to the $\Delta G^{298}$ values, entropy effects due to the different conformations must be considered small.

Considering $\Delta \Delta G^{298}$ values for 1 -azoniahexa-1,5-diene (2), the energies of the individual conformers scatter over a range of $3.1 \mathrm{kcal} \mathrm{mol}^{-1}$, which is even less than for $\mathbf{1}$. Structure $\mathbf{2 a}$ clearly dominates the product distribution in the gas phase. Since this structure will be reached first after passing the chair-like transition state, it is the most important conformer on the product side. We were not able to locate a structure corresponding to $\mathbf{1} \mathbf{f}$, since all attempts led to conformer $\mathbf{2 a}$. Solvation free energies scatter over a much broader range than the relative total energies and, thus, determine the preferred conformer in solution. According to the SCRF/B3LYP calculations the most stable conformer is 21 . This result is supported by the large (gas phase) dipole moment of this conformer. In general, dipole moments for $\mathbf{2}$ are significantly larger than for 1 . The reaction energy (i.e. $\Delta E_{0}$ without ZPE and thermal corrections) at the B3-LYP/cc-pVTZ level is $-14.7 \mathrm{kcalmol}^{-1}$ and $-14.2 \mathrm{kcalmol}^{-1}$ at the LMP2/cc-pVTZ level. These values differ considerably from the result Walters ${ }^{[34}$ obtained at the MP2/6-311G* level $\left(\Delta E_{0}=\right.$ $-10.3$

Together with the structures of the most stable reactant and product conformers in the gas phase, the structures of the 
chair-like and boat-like transition states are provided in Figure 2. Since both these structures are chiral they again exist as isoenergetic enantiomers; only one of them is shown. For the last two structures the interatomic distances of the forming and breaking bonds are considerably longer than found by Walters ${ }^{[34]}$ at the MP2 level. For the chair-like structures he obtained values of 2.289 and $1.994 \AA$, respectively, while the B3-LYP functional used in this study provides distances of 2.577 and $2.201 \AA$. In a recent study of an intramolecular rearrangement of 4-nitro-benzofuroxan, ${ }^{[64]}$ we found that transition-state bond lengths are very similar between MP4(SDQ) and B3-LYP structures, while MP2 leads to shorter distances. However, there is still a slight tendency of the hybrid exchange-correlation functional to systematically overestimate bond lengths. ${ }^{[58]}$ In complete agreement with Walters study, we find a significantly longer value for the forming $\mathrm{C}-\mathrm{C}$ bond than the breaking $\mathrm{C}-\mathrm{N}$ bond. Moreover, the interatomic distances for these coordinates are longer for the boat-like transition state than for the chair-like one, which is particularly true for the forming $\mathrm{C}-\mathrm{C}$ bond which is computed as $2.701 \AA$ at the B3-LYP/cc-pVDZ level.

The best estimate of the free activation energy (obtained from $\operatorname{CCSD}(T) / c c-p V T Z(f, p)$ calculations corrected by scaled B3-LYP/cc-pVDZ ZPEs and corresponding thermodynamic contributions) is $21.9 \mathrm{kcalmol}^{-1}$ (c.f. Table 3) and is in excellent agreement with Walters results. The B3-LYP barrier is significantly lower, indicating that electron correlation effects are not sufficiently accounted for at this level. As already pointed out by Radom et al. ${ }^{[65]}$ and Bell et al., ${ }^{[66]}$ this effect is frequently encountered. Comparing Walters activation energies at the MP2/6-311 G* level with the LMP2/ccpVTZ values of this study one obtains a difference of $1.4 \mathrm{kcalmol}^{-1}$. The higher value of the LMP2 calculations must be addressed to the choice of the reference structure and
Table 3. Relative energies, ${ }^{\text {,a] }}$ solvation free energies, and dipole moments of the Cope transition states of 1 toward 2 .

\begin{tabular}{|c|c|c|c|c|c|c|}
\hline & $\Delta E_{\mathrm{DYT}}$ & $\Delta E_{\text {LMP2 }}$ & $\Delta E_{C(\mathrm{~T})}$ & $\Delta \Delta G_{C \operatorname{CSI}(\mathrm{T})}[\mathrm{bl}$ & $\triangle \triangle C_{\mathrm{H}}^{\mathrm{m} / \mathrm{F}}$ & $\Delta G_{\mathrm{DF}}^{\text {salp }}[0]$ \\
\hline $\operatorname{TS}$ (ch & 16.76 & 19.63 & 22.35 & 21.93 & 16.34 & -56.66 \\
\hline TS(boat) & 19.53 & 25.40 & 26.87 & 25.78 & 18.43 & -55.98 \\
\hline
\end{tabular}

[a] All data refer to the cc-pVTZ basis and are given in $\mathrm{kcal} \mathrm{mol}^{-1}$. Reference structure is 1 a. [b] Zero-point vibrational energies (scaled by 0.963 ) and thermal corrections were transferred from B3-LYP/cc-pVDZ calculations. [c] Free energy of solvation, to be added to the total free energy of the molecule.

to the different geometrical parameters of the transition state. Of particular interest is the solvation effect on the transition states. As has been noted before, dipole moments are slightly smaller for these structures than for most conformers of the reactant owing to the increased dissipation of the overall positive charge. As a consequence the solvation free energy is also significantly lower, and this shifts the activation barrier of this reaction by up to $5.6 \mathrm{kcal} \mathrm{mol}^{-1}$ to higher values in a polar solvent.

The molecular rearrangement of 3-azoniahex-1-ene-5-yne: The rearrangement of 3-azoniahex-1-ene-5-yne (3) to 1-azoniahexa-1,4,5-triene (4) is shown formally in Scheme 3. Again, conformers which do not show $C_{\mathrm{s}}$ symmetry are pairwise identical in energy. Moreover, this potential-energy surface allows for two enantiomeric transition states corresponding to aza-Cope rearrangements, one of them being depicted in<smiles>C#CC[NH2+]C=C</smiles>

Scheme 3. The Cope rearrangement of 3-azoniahexa-1-ene-5myne.

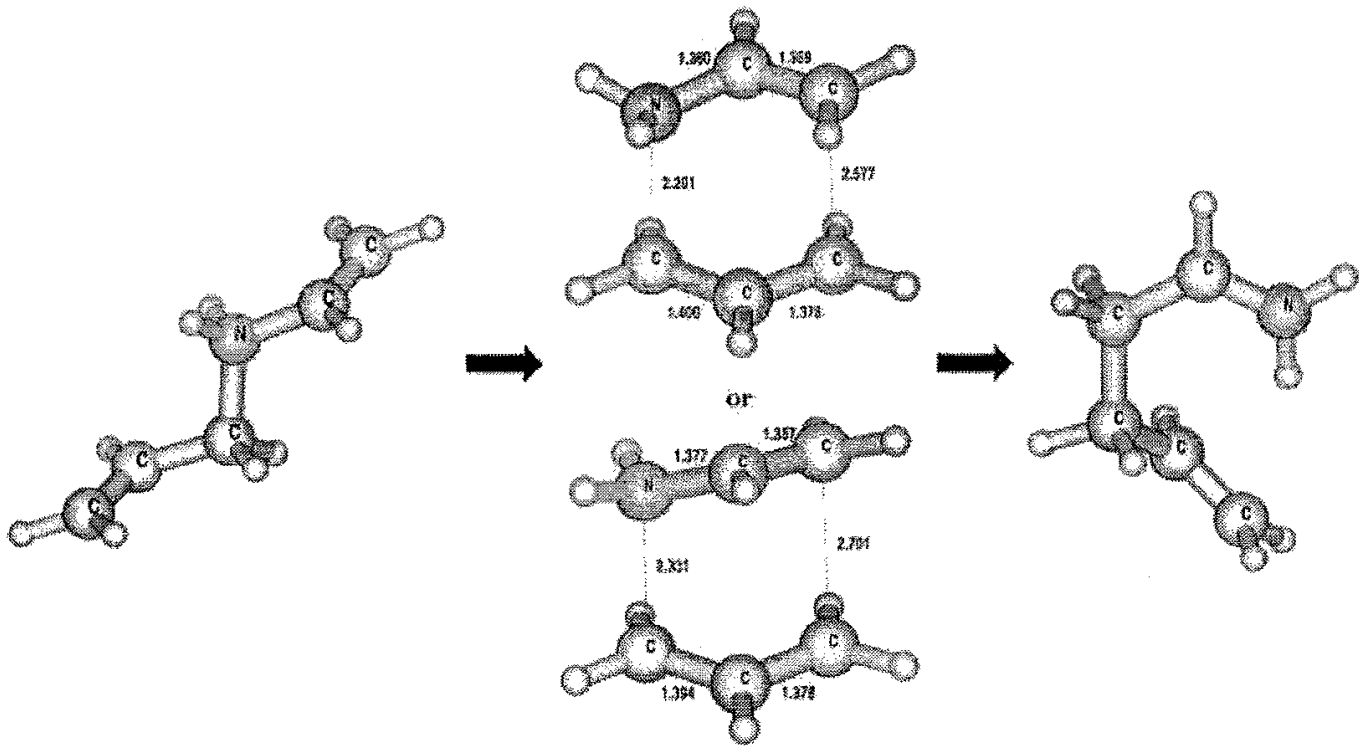




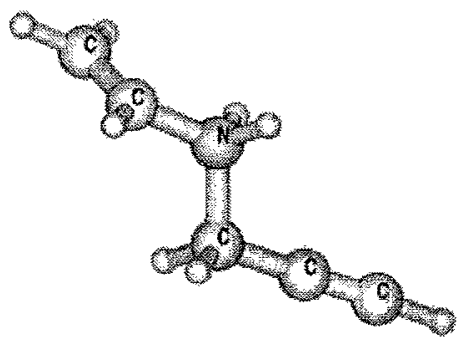

3a.

Figure 3. The Cope rearrangement of 3 .

Figure 3. As observed for the reaction of $\mathbf{1}$ the conformers lowest in energy do not necessarily constitute the direct precursor and successor of the reaction. The direct precursor of this rearrangement is $\mathbf{3 c}$, but the first local minimum on the product side is described by $4 \mathbf{a}$, which is the most stable conformer in the gas phase.

Table 4 summarizes all structures and energies computed for the Cope rearrangement of $\mathbf{3}$. Figure 3 shows all structures involved in the gas-phase reaction. This illustration demonstrates that the overall reaction consists of a rotation of the linear structural motif around the central $\mathrm{C}-\mathrm{N}$ bond and the bond breaking/formation process. The interatomic distances of the cleaving and forming bonds in the transition state are slightly shorter than those found for the reaction of 1 . Our best estimate of the free activation energy is $24.3 \mathrm{kcal} \mathrm{mol}^{-1}$, which is about $3.5 \mathrm{kcalmol}^{-1}$ higher in energy than the corresponding value for the conversion of 1 into 2 . This may also account for the fact that the rearrangement of trans $-\left[\mathrm{Cl}(\mathrm{dppm})_{2} \mathrm{Ru}-\mathrm{C} \equiv \mathrm{C}-\mathrm{C}\left(=\mathrm{CH}_{2}\right)\left(\mathrm{NMe}_{2} \mathrm{CH}_{2} \mathrm{CH}=\mathrm{CH}_{2}\right)\right]^{+}$ cleanly proceeds under ambient conditions, while its propargylic analog, trans $-\left[\mathrm{Cl}(\mathrm{dppm})_{2} \mathrm{Ru}-\mathrm{C} \equiv \mathrm{C}-\mathrm{C}\left(=\mathrm{CH}_{2}\right)-\right.$ $\left.\left(\mathrm{NMe}_{2} \mathrm{CH}_{2} \mathrm{C} \equiv \mathrm{C}-\mathrm{C}_{2} \mathrm{H}_{5}\right)\right]^{+}$, requires thermal activation to pro-

Table 4. Structures ${ }^{[a]}$ involved in the Cope rearrangement of 3

\begin{tabular}{|c|c|c|c|c|c|c|c|c|}
\hline & $\alpha^{b !}$ & $\beta^{[0]}$ & $\Delta E_{\mathrm{DF}}[\mathrm{s}]$ & $\Delta E_{\text {LAtP2 }}{ }^{[0]}$ & $\Delta E_{\mathrm{Ccs}(\mathrm{T})}$ & $\Delta \Delta G_{\mathrm{DFT}}^{298}[\epsilon]$ & $\Delta \Delta G_{\mathrm{DFT}}^{\mathrm{soly}}{ }^{\mathrm{t} t \mathrm{t}}$ & $\mu^{\mathrm{tg}}$ \\
\hline 3a & -114.7 & -178.9 & 0.00 & 0.00 & $0.00(0.00)$ & 0.00 & -62.10 & 2.08 \\
\hline $3 \mathbf{b}$ & -119.6 & -67.5 & 0.72 & 0.29 & & 0.82 & -61.80 & 3.05 \\
\hline $3 c$ & -114.7 & 69.1 & 1.07 & 0.52 & & 1.08 & -63.37 & 3.23 \\
\hline 3d & 0.0 & 180.0 & 2.00 & 1.68 & & 2.35 & -61.89 & 2.26 \\
\hline $3 e$ & -3.1 & 73.0 & 3.15 & 2.32 & & 3.58 & -63.34 & 3.41 \\
\hline TS & & & 19.59 & 20.85 & $25.42(24.32)^{[\mathrm{h}]}$ & 18.49 & -56.54 & 2.38 \\
\hline $4 a$ & 7.6 & -101.7 & -23.59 & $-23.91^{[1]}$ & & -24.25 & -60.78 & 5.63 \\
\hline $4 b$ & 0.0 & 0.0 & -23.16 & $-23.46^{(i)}$ & & -23.46 & -56.53 & 4.67 \\
\hline $4 c$ & -110.7 & 85.2 & -22.45 & $-22.11^{\{i]}$ & & -23.17 & -62.23 & 5.23 \\
\hline $4 d$ & -103.7 & -99.4 & -22.32 & $-22.08^{|i|}$ & & -22.92 & -60.93 & 5.89 \\
\hline
\end{tabular}

[a] All data refer to the cc-pVTZ basis sel. All energies refer to $3 a$ and are given in $\mathrm{kcalmol}^{-1}$. [b] The dihedrals $\alpha, \beta$, and $\gamma$ specify the conformation of the structure. [c] Total B3-LYP/cc-pVTZ energy of 3a: -249.8401803 a.u. [d] Total MP2/ccpVTZ energy of 3a: -249.1951592 a.u. [e] Zero-point vibrational energies and thermal correction were transferred fr $m$ B 3-LYP/cc-pVDZ calculations. [f] Free energy of solvation, to be added to the total free energy of the molecule. [g] Dipole moments are provided in Debye. [h] Value in parenthesis is corrected by zero-point vibrational energies (scaled by 0.963 ) and thermal corrections taken from B3-LYP/ cc-pVDZ calculations. [i] See text body for a detailed description of the generation of these values.

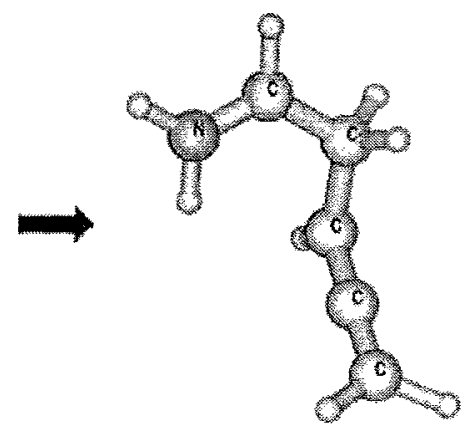

$4 a$

ceed in reasonable time. Again, DFT calculations underestimate the reaction barrier. The reaction energy is about $-24 \mathrm{kcalmol}^{-1}$ and, thus, shows a significantly enhanced exothermicity in comparison to the conversion of 1 into 2 $\left(-14 \mathrm{kcalmol}^{-1}\right)$. Due to strong changes in the orbital domains within the reaction of $\mathbf{3}$ toward $\mathbf{4}$, we computed the reaction energy of $\mathbf{4 a}$ relative to $\mathbf{3 a}$ at the conventional MP2 level, but used LMP2 energies to determine the relative energy differences due to conformational changes of 4 . Again, polar solvents lead to an increase of the activation barrier. Although the gas-phase dipole moments for $\mathbf{4}$ are much larger than for 3, SCRF/B3-LYP calculations do not predict significantly larger free solvation enthalpies for 4 . Since the free solvation energy is a function of several contributions other than the pure electrostatic energy, the absolute value of the total free solvation energy cannot necessarily be directly related to the dipole moment.

The molecular rearrangement of 3-azahex-1-ene-5-yne: The rearrangement of 3-azahexa-1-ene-5-yne (5) to 1-azahexa1,4,5-triene (6) is shown formally in Scheme 4. The most

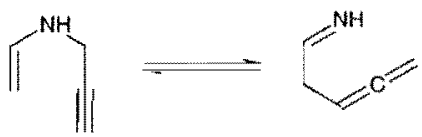

Scheme 4. The Cope rearrangement of 3-az hexa-1-ene-5-yne.

important conformers of the reactant and product of this reaction are summarized in Table 5 . With respect to the reaction mechanism, the molecular rearrangement of 3-azahex-1-ene-5-yne is the most interesting case in our study. Two different reaction paths were found. As a result of the triplebond moiety in the reactant, it is difficult to assign these two reaction paths as proceeding via chair-like or boat-like transition states, as in the case of 1,5-hexadiene and related compounds. However, according to our DFT and $\operatorname{CCSD}(\mathrm{T})$ calculations the energetically preferred pathway is described by a stepwise mechanism forming a boat-like transition state TS a first, passing the intermediate INT, and finally forming a second halfchair-like transition state. This provides a very rare example of Cope-type rearrangements occurring by a stepwise mechanism. ${ }^{\mid 43,47.48\}}$ The structures of the transition states 
Table 5. Structures ${ }^{(x)}$ involved in the Cope rearrangement of 5.

\begin{tabular}{|c|c|c|c|c|c|c|c|c|c|}
\hline & $\alpha^{(b)}$ & $\beta^{[\mathrm{b}]}$ & $\gamma^{[\mathrm{b}]}$ & $\Delta E_{\mathrm{DF}} \mathrm{F}^{(\mathrm{cl})}$ & $\Delta E_{\mathrm{LMP2}}{ }^{[\mathrm{d}]}$ & $\Delta E_{\text {cesu(n) }}$ & $\Delta \Delta G_{\mathrm{DFT}}^{29 \mathrm{~F}}$ & $\Delta G_{\mathrm{DFT}}^{\text {solv }}[\mathrm{n}$ & $\mu^{[\varepsilon]}$ \\
\hline $5 \mathrm{a}$ & & 12.6 & 175.0 & 0.00 & 0.00 & $0.00(0.08)$ & 0.00 & $-3.5]$ & 1.16 \\
\hline $5 \mathrm{~b}$ & & 11.2 & 71.5 & 0.72 & 0.17 & & 0.77 & -5.60 & 1.33 \\
\hline $5 \mathrm{c}$ & & -149.6 & 74.2 & 0.75 & 0.80 & & 0.45 & -5.55 & 1.03 \\
\hline $5 d$ & & 147.7 & 170.2 & 1.40 & 0.79 & & 1.01 & -4.62 & 1.04 \\
\hline $5 e$ & & -15.8 & 83.4 & 1.62 & 1.15 & & 1.47 & -4.92 & 1.81 \\
\hline $5 f$ & & 147.1 & 64.2 & 2.18 & 2.10 & & 1.85 & -5.18 & 1.42 \\
\hline TSa & & & & 29.12 & 27.40 & $28.11(29.45)^{[\mathrm{b}]}$ & 30.46 & -9.88 & 2.98 \\
\hline TSb & & & & 27.35 & 30.10 & $27.98(29.50)^{[\mathrm{b}]}$ & 28.87 & -8.72 & 3.88 \\
\hline TSc & & & & 36.08 & 29.29 & $33.25(34.06)^{(\mathrm{h})}$ & 36.89 & -10.66 & 1.23 \\
\hline INT & & & & 26.81 & 30.57 & $26.94(28.98)^{(\mathrm{h})}$ & 28.85 & -11.61 & 4.62 \\
\hline $6 \mathrm{a}$ & 179.7 & -118.0 & -114.0 & -11.62 & $-14.17^{14}$ & & -12.34 & -4.52 & 1.81 \\
\hline $6 \mathrm{~b}$ & -178.8 & -4.6 & -140.6 & -11.18 & $-13.58^{[i]}$ & & -12.03 & -6.42 & 2.12 \\
\hline $6 c$ & 0.0 & 10.9 & -113.8 & -11.16 & $-13.91^{11}$ & & -11.77 & -5.23 & 2.51 \\
\hline $6 d$ & -179.6 & -127.9 & 118.1 & -10.87 & נויו 13.01 - & & -11.78 & -7.93 & 1.82 \\
\hline $6 e$ & -0.1 & -120.6 & -114.0 & -10.73 & $-12.80^{[i]}$ & & -11.52 & -7.73 & 2.37 \\
\hline $6 f$ & -179.0 & -127.2 & 9.5 & -10.70 & $-13.55^{[i]}$ & & -11.11 & -5.19 & 1.79 \\
\hline 68 & 0.7 & -127.4 & 117.8 & -10.33 & $-12.73^{[i]}$ & & -11.26 & -8.99 & 2.33 \\
\hline $6 \mathrm{~h}$ & 1.5 & -127.8 & 10.8 & -9.76 & -10.7719 & & -10.67 & -7.27 & 2.33 \\
\hline
\end{tabular}

[a] All data refer to the cc-pVTZ basis set. All energies refer to 5 a and are given in kcal mol ' ${ }^{4}$. [b] The dihedrals $\alpha, \beta$, and $\gamma$ specify the confonmation of the structure. [c] Total B3-LYP/cc-pVTZ energy of 5a: -249.4904593 a.u. [d] Total LMP2/cc-pVTZ energy of 5a: - 248.846772I a.u. [e] Zero-point vibrational energies and thermal correction were transferred from B3-LYP/cc-pVDZ calculations. [f] Free energy of solvation, to be added to the total free energy of the molecule. [g] Dipole moments are provided in Debye. [h] Value in parenthesis is corrected by zero point vibrational energies (scaled by 0.963 ) and thermal corrections taken from B3-LYP/cc-pVDZ calculations. [i] See text body for a detailed description of the generation of these values.

(TSa and TSb) involved in the first mechanism are provided in Figure 4. In agreement with others, Jiao and Schleyer ${ }^{[42]}$ point out that the nature of the stationary points of the transition states in the Cope rearrangement of simple hydrocarbons are very sensitive with respect to the computational level, and the inclusion of dynamical electron correlation appears to be mandatory. They used the same hybrid exchange-correlation functional as we did and found onestep mechanisms in each case. In contrast, the Cope rearrangement of 3-azahex-1-ene-5-yne indeed proceeds by a stepwise mechanism. Since the energetical differences between INT and TSb are very small (c.f. Table 5), we additionally optimized the structures of these two molecules at the MP4(SDQ)/cc-pVDZ level and performed single-point energy calculations at the CASPT2 and CCSD(T) levels for both sets of geometries. In all cases (i.e. different geometries and different computational levels of the single-point energy calculations) the structure of the intermediate INT was found to be about $\Delta E=0.5$ (B3-LYP) to $\Delta E=1$.

(CASPT2) lower in energy than transition state TSb. There- fore, we conclude that this intermediate is not an artifact of the methods applied, but is indeed physically existent. ZPE corrections lead to a further destabilisation of the intermediate, but solvent effects tend to overcompensate for this effect. However, due to the extremely low barrier between INT and TSb it will never be possible to trap this intermediate experimentally. Nevertheless, our findings indicate a change of the mechanism upon the protonation of 3-azahex-1-ene-5yne and provide one of the very few intermediates that characterize a stepwise Cope rearrangement. Considering its structure as given in Table 6 and Figure 5, this intermediate is truly remarkable. The $\mathrm{C} 3-\mathrm{C} 6$ bond is predicted to be about $1.620 \AA$ at both levels of theory. The $\mathrm{C} 1-\mathrm{C} 2$ bond is the one that is most sensitive toward the computational method employed. According to the occupation numbers of the CASSCF natural orbitals (HOMO: 1.81; LUMO: 0.20) and the leading contributions to the $\mathrm{CI}$ vector, this structure is definitely not a biradical. The first three configurations of the $\mathrm{Cl}$ vector are closed-shell in nature and their coefficients are given as $0.914,-0.273$, and -0.153 , whereas the coeffcient of

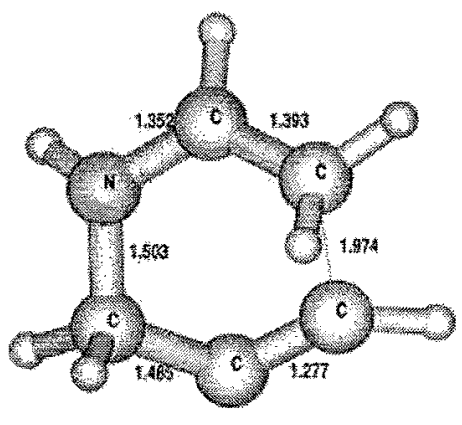

TSt

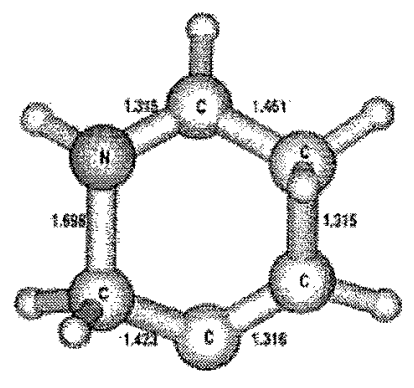

TSb

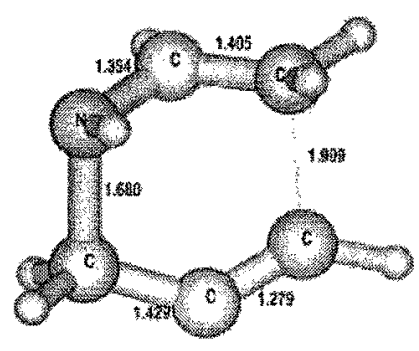

$\operatorname{Tsc}$

Figure 4. Structures and structural parameters [in $\AA$ ] of the three main transition states of the Cope rearrangement between 5 and 6. 
Table 6. Geometrical parameters of intermediate INT:[a]

\begin{tabular}{|c|c|c|c|c|c|c|c|c|}
\hline Bond $^{(b)}$ & B3-LYP & MP4(SDQ) & Angletw & B3-LYP & MP4(SDQ) & Dihedral ${ }^{[b]}$ & B3-LYP & MP4(SDO) \\
\hline $\mathrm{N}_{4}-\mathrm{C}_{i}$ & 1.525 & 1.511 & $\mathrm{~N}_{4}-\mathrm{C}_{1}-\mathrm{C}_{2}$ & 113.0 & 112.8 & $\mathrm{~N}_{4}-\mathrm{C}_{1}-\mathrm{C}_{2}-\mathrm{C}_{3}$ & 27.7 & 31.5 \\
\hline$C_{1}-C_{2}$ & 1.482 & 1.509 & $C_{1}-C_{2}-C_{3}$ & 118.5 & 115.5 & $\mathrm{C}_{1}-\mathrm{C}_{2}-\mathrm{C}_{3}-\mathrm{C}_{6}$ & 6.1 & 6.8 \\
\hline $\mathrm{C}_{2}-\mathrm{C}_{3}$ & 1.318 & 1.332 & $C_{2}-C_{3}-C_{6 i}$ & 119.2 & 119.7 & $\mathrm{C}_{2}-\mathrm{C}_{3}-\mathrm{C}_{6} \cdot \mathrm{C}_{5}$ & -44.7 & -48.0 \\
\hline $\mathrm{C}_{3}-\mathrm{C}_{6}$ & 1.620 & 1.619 & $\mathrm{C}_{3}-\mathrm{C}_{6} \cdot \mathrm{C}_{5}$ & 105.0 & 103.8 & $\mathrm{C}_{3}+\mathrm{C}_{6}-\mathrm{C}_{5}-\mathrm{N}_{4}$ & 50.8 & 52.3 \\
\hline $\mathrm{C}_{6}-\mathrm{C}_{5}$ & 1.451 & 1.457 & $\mathrm{C}_{6}-\mathrm{C}_{5}-\mathrm{N}_{4}$ & 118.5 & 117.8 & $\mathrm{C}_{6}-\mathrm{C}_{5}-\mathrm{N}_{4}-\mathrm{C}_{4}$ & -20.5 & -17.9 \\
\hline $\mathrm{C}_{5}-\mathrm{N}_{4}$ & 1.326 & 1.322 & $\mathrm{C}_{5}-\mathrm{N}_{4}-\mathrm{C}_{1}$ & 120.1 & 120.1 & $\mathrm{C}_{5}-\mathrm{N}_{4}-\mathrm{C}_{1}-\mathrm{C}_{2}$ & -22.4 & -28.3 \\
\hline
\end{tabular}

[a] For the labcling of the atoms sec Figure 5. [b] Bond lengths in $\AA$, angles and dihedral angles in degree.

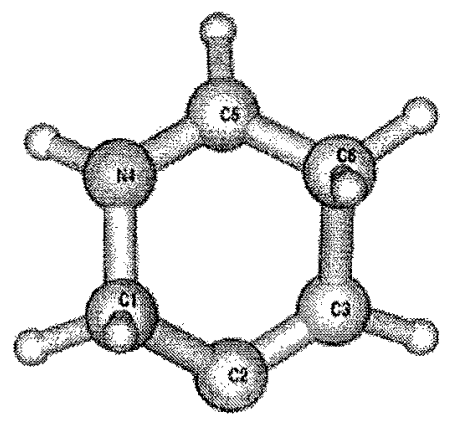

Figure 5. Structure and labeling of intermediate $\mathbf{N T}$.

the first open-shell configuration is 0.056 only. Analogous arguments hold true for the corresponding transition state TSb. To the best of our knowledge the only other stepwise Cope rearrangement via a non-biradical intermediate has been reported by Walters for the 1-aza-1,5-hexadienyl anion. ${ }^{[43]}$ As confirmed by GIAO/B3-LYP/cc-pVTZ calculations of the nuclear independent chemical shift (NICS) $)^{[67,68]}$ at the ring critical point ${ }^{[67]}(-11.3 \mathrm{ppm})$, the intermediate $\mathbf{I N T}$ is clearly aromatic in nature.

An alternative one-step reaction path was found to proceed via transition state TS c (c.f. Figure 4). However, the barrier of this concerted mechanism is consideraby higher than for the stepwise mechanism and must thus be considered less important for this reaction.

Relative energies for this reaction are provided in Table 5 and the structures of the most stable conformers of the reactant and the product are shown in Figure 6. Since all structures involved in this particular reaction are uncharged, the solvation free energies are about one order of magnitude lower than for the other two rearrangements. The best estimate for $\Delta G^{+}$is $29.5 \mathrm{kcal} \mathrm{mol}^{-1}$ and $-12.3 \mathrm{kcalmol}^{-1}$ for the reaction free energy $\left(\Delta G_{0}\right)$. According to these values protonation of 4 lowers the activation energy by just $5.2 \mathrm{kcal} \mathrm{mol}^{-1}$, which is about one third of the value discussed in the literature ${ }^{[17]}$ for $\mathrm{N}$-allylanilines. High electron correlation effects appear to have little effect on this reaction, and, consequently, the DFT barrier is rather close to the $\operatorname{CCSD}(\mathrm{T})$ value. Interestingly, solvation effects appear to lower the reaction barrier rather than increasing it as observed for the first two rearrangements. According to the SCRF calculation the barrier is about $5 \mathrm{kcal} \mathrm{mol}^{-1}$ lower in energy in aqueous solution. Moreover, considering the moderate decrease of the activation energy upon protonation, the activation energy in aqueous solution may unexpectedly even be lower for the unprotonated form. According to the Hammond postulate the higher activation energy corresponds to a smaller reaction energy when compared to the comparable reaction of the protonated species 3 .

An almost constant difference of about $2.5 \mathrm{kcalmol}^{-1}$ between the B3-LYP and LMP2 relative energies of 6 can be observed. However, differences of this magnitude are still within the range of the inherent errors of these methods and are not unexpected. The relative LMP2 energies of 6 were obtained as described for 4 in the previous section and give a different order for the conformers of 6 than derived from the DFT relative stabilities. While relative energies $\Delta E_{\mathrm{DFT}}$ for 6 are rather similar, scattering only within $1.9 \mathrm{kcal} \mathrm{mol}^{-1}$, the corresponding range of the solvation free energies is considerably larger and extends to about $4.5 \mathrm{kcal} \mathrm{mol}^{-1}$. Consequently, in solution the preferred conformer is mainly determined by solvation effects rather than its relative stability in the gas phase.

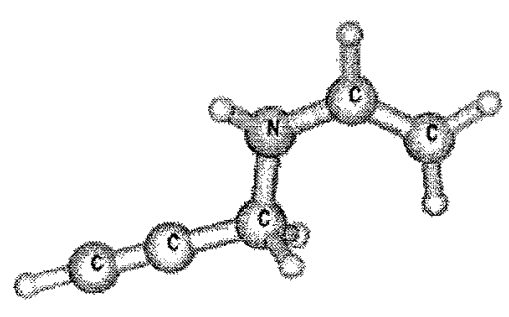

5

Figure 6. Lowest energy conformers of 5 and $\mathbf{6}$ in the gas phase.

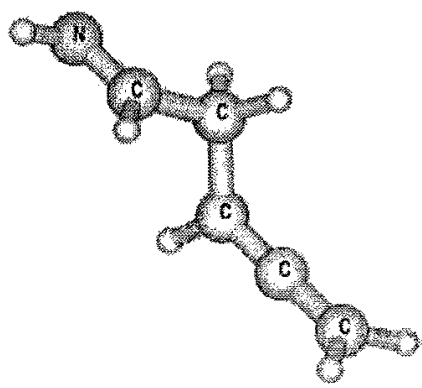

$6:$

\section{Conclusion}

Three aza-Cope rearrangements were investigated by computational methods up to the $\operatorname{CCSD}(T) / c c-p V T Z(f, p)$ level. Since the activation barrier is significantly lower for these reactions than for the corresponding hydrocarbons, conformational studies appear to be an essential prerequisite for a sound estimation of the barrier height. The most reliable values for the gas phase 
reaction of 3-azoniahexa-1,5-diene (1), 3-azoniahex-1-ene-5yne (3), and 3-azahex-1-ene-5-yne (5) are $\Delta G^{\ddagger}=21.9,24.3$, and $29.5 \mathrm{kcal} \mathrm{mol}^{-1}$, respectively. For the barriers corresponding to the Cope rearrangements of the protonated species, B3LYP calculations lead to an underestimation of the activation energies indicating that electron correlation effects are not sufficiently been accounted for at this level. The activation barrier of the protonated species 3 is only $5.2 \mathrm{kcalmol}^{-1}$ lower than for 5. This value is significantly smaller than that observed for the systems investigated by Jolidon et al. ${ }^{[1]}$ who report changes of $15-17 \mathrm{kcalmol}^{-1}$. However, the same authors report activation entropies of -13 to $-19 \mathrm{eu}$ for their species, while our values and those of Walters ${ }^{[34]}$ are between -4.4 and $-7.8 \mathrm{cal} \mathrm{K}^{-1} \mathrm{~mol}^{-1}$

$-5.4 \mathrm{cal} \mathrm{K}^{-1} \mathrm{~mol}^{-1} ; \quad \Delta S^{+} \quad(3 \rightarrow 4): \quad-4.4 \mathrm{cal} \mathrm{K}^{-1} \mathrm{~mol}^{-1} ; \Delta S^{+}$ $\left.(5 \rightarrow 6):-7.4 \mathrm{cal} \mathrm{K}^{-1} \mathrm{~mol}^{-1}\right)$. Furthermore, solvation effects appear to have considerable impact on the activation barrier: depending on their dielectric constant polar solvents lead to an increase of the barriers by several $\mathrm{kcal} \mathrm{mol}^{-1}$ for the protonated species, while lowering the activation barrier of the neutral compound. This result is in agreement with the studies of Hillier etal. ${ }^{[70]}$ and others ${ }^{[71,72]}$ on the solvent dependence of the Claisen rearrangement. The low activation energies of the protonated forms relative to their neutral counterparts arises mainly from the higher charge delocalization in the transition state of the former. Therefore, solvation may alter the relative order of the activation barriers of the protonated and the neutral species.

Computer time provided by the Institut für Theoretische Chemie at the Universität Stuttgart $(G)$ is kindly acknowledged. The authors thank the Fonds der Chemischen Industrie, the Deutsche Forschungsgemeinschaft and the Volkswagenstiftung for financial support.

(1) J. Ficini, C. Barbara, Tetrahedron Lett. 1966, 6425

[2] R. K. Hill, N. W. Gilman, Tetrahedron Lett. 1967, 1421

[3] R. Gompper, B. Kohl. Angew. Chem. 1982, 94, 202; Angew. Chem. Int. Ed. Engl. 1982, 21, 198.

[4] M. J. Kurth, O. H. W. Decker, H. Hope. M. D. Yanuck, J. Am. Chem. Soc. 1985, 107, 443 .

[5] G. R. Cook, J. R. Stille, J. Org. Chem. 1991, 56, 5578.

[6] N. S. Barta, G. R. Cook, M. S. Landis, J. R. Stille, J. Org. Chem. 1992, 57, 7188.

[7] J. Corbier, P. Cresson, C. R. Seances Acad. Sci. Ser. C 1970, 270, 2077.

[8] G. Opitz, Justus Liebigs Ann. Chem. 1961, 650, 122.

[9] M. J. Kurth, O. H. W. Decker. J. Org. Chem. 1986, 51, 1377.

[10] J. Corbier, P. Cresson, P. C. Jelenc, C. R. Seances Acad. Sci. Ser C 1970, $270,1890$.

[11] R. E. Ireland, A. K. Willard, J. Org. Chem. 1974, 39, 421.

[12] T. Tsunoda, O. Sasaki, S. Itoh, Tetrahedron Lett. 1990, 31, 727.

[13] J. R. Hwu, D. A. Anderson, Tetrahedron Lett. 1986, 27, 4965.

[14] H. Heimgartner, H.-J. Hansen, H. Schmid, Adv. Org. Chem. 1979, 9, 655.

[15] R. P. Lutz, Chem. Rev. 1984, 84, 205.

[16] G. B. Bennett, Synthesis 1977, 589.

[17] S. Jolidon, H.-J. Hansen, Helv. Chim. Acta 1977, 60, 978.

[18] G. R. Cook, N. S. Barta, J. R. Stille, J. Org. Chem. 1992, 57, 461.

[19] R. K. Hill, H. N. Khatri, Tetrahedron Lett. 1978, 4337.

[20] L. G. Beholz, J. R. Stille, J. Org. Chem. 1993, 58, 5095.

[21] G. Opitz, H. Mildenberger, Angew. Chem. 1960, 72, 169.

[22] G. Opitz. H. Mildenberger, Justus Liebigs Ann. Chem. 1961, 649, 26.

[23] G. Opitz, H. Hellmann, H. Mildenberger, H. Suhr, Justus Liebigs Ann. Chem. 1961, 649, 36

[24] G. Opitz, Justus Liebigs Ann. Chem. 1961. 649, 122.
[25] E. Elkik, Bull. Soc. Chim. Fr. 1960, 972.

[26] E. Elkik, C. R. Seances Acad. Sci. Ser. C 1969, $268,1614$.

[27] E. Elkik, C. Francesch, Bull. Soc. Chim. Fr. 1969, 903

[28] K. C. Brannock, R. D. Burpitt, J. Org. Chem. 1961, 26, 3576.

[29] P. M. McCurry, Jr., R. K. Singh, Tetrahedron Lett. 1973, 3325.

[30] J. C. Gilbert, K. P. A. Senaratne, Tetrahedron Lett. 1984, 25, 2303.

[31] E. Vedejs, M. Gingras, J. Am. Chem. Soc. 1994, 116, 579.

[32] S.-I. Murahashi, Y. Makabe, K. Kunita, J. Org. Chem. 1988, 53, 4489.

[33] R. F. Winter. F. M. Hornung, Organometallics 1997, 16, 4248.

[34] M. A. Walters, J. Org. Chem. 1996, 61, 978.

[35] A. Komornicki, J. W. Mclver, Jr.. J. Am. Chem. Soc. 1976, 98, 4553.

[36] K. Morokuma, W. T. Bordon, D. A. Hrovat, J. Am. Chem. Soc. 1988. 110,4474

[37] K. A. Owens, J. A. Berson, J. Am. Chem. Soc. 1990, 112, 5973.

[38] K. N. Houk, S. M. Gustafson, K. A. Black, J. Am. Chem. Soc. 1992, 114,8565 ,

[39] D. A. Hrovat, K. Morokuma, W. T. Borden, J. Am. Chem. Soc. 1994, 116, 1072.

[40] O. Wiest, K. A. Black, K. N. Houk, J. Am. Chem. Soc. 1994, 116 10336.

[41] P. M. Kozlowski, M. Dupuis, E. R. Davidson, J. Am. Chem. Soc. 1995 , $117,774$.

[42] H. Jiao, P. von R. Schleyer, Angew. Chem. 1995, 107, 329; Angew. Chem. Int. Ed. Engl. 1995, 34, 334.

[43] M. A. Waiters, Tetrahedron Lett. 1995, 36, 7055.

[44] W. T. Borden, E. R. Davidson, Acc. Chem. Res. 1996, 29.67.

[45] H. Jiao, R. Nagelkerke, H. A. Kurtz, R. V. Williams. W. T. Borden, P. v. R. Schleyer, J. Am. Chem. Soc. 1997, 119. 5921.

[46] K. A. Black. S. Wilsey, K. N. Houk, J. Am. Chem. Soc. 1998, 120, 5622.

[47] J. A. Duncan, J. K. Azar, J. C. Beathe, S. R. Kennedy, C. M. Wulf, J. Am. Chem. Soc. 1999, 121, 12029.

[48] D. A. Hrovat, J. A. Duncan, W. T. Borden, J. Am. Chem. Soc. 1999. $121,169$.

[49] S. Sakai, Int. J. Quantum Chem. 2000, 80, 1099.

[50] B. W. Gung, Z. Zhu. R. A. Fouch, J. Am. Chem. Soc. 1995, 117, 1783.

[51] G. D. Smith, W. Paul, J. Phys. Chem. A 1998, 102, 1200.

[52] A. D. Becke, J. Chem. Phys. 1993. 98. 5648.

[53] T. Dunning, J. Chem. Phys. 1989, 90, 1007.

[54] P. Pulay, S. Sxbø, Theor. Chim. Actu 1986, 69, 357

[55] A. El Azhary, G. Rauhut, P. Pulay, H.-J. Werner, J. Chem. Phys. 1998 108,5185 .

[56] G. Rauhut, A. El Azhary, F. Eckert, U. Schumann, H.-J. Wemer Spectrochim. Acta A 1999, 55, 647.

[57] J. W. Boughton, P. Pulay, J. Comput. Chem. 1993. 14. 736.

[58] G. Rauhut, P. Pulay. J. Phys. Chem. 1995, 99, 3093.

[59] F. Celani, H.-J. Werner, J. Chem. Phys. 2000, 112, 5546.

[60] S. Miertus, J. Tomasi, Chem. Phys. 1981, 55, 117.

[61] S. Miertus, E. Scrocco, J. Tomasi, Chem. Phys. 1982, 65, 239.

[62] Molpro is a package of $a b$ initio programs written by H.-J. Werner and P. J. Knowles, with contributions from R. D. Amos, A. Berning, D. L. Cooper, M. J. O. Deegan, A. J. Dobbyn, F. Eckert, C. Hampel, G. Hetzer, T. Leininger, R. Lindh, A. W. Lloyd, W. Meyer, M. E. Mura, A. Nicklass, P. Palmieri, K. Peterson, R. Pitzer, P. Pulay, G. Rauhut, M. Schütz, H. Stoll. A.J. Stone, T. Thorsteinsson, Version 2000.4, University of Birmingham, UK, 1999. (see http://www.tc.bham.ac.uk/molpro/)

[63] M. J. Frisch, G. W. Trucks, H. B. Schlegel, P. M. W. Gill, B. G. Johnson, M. A. Robb, J. R. Cheeseman, T. Keith, G. A. Petersson, J. A. Montgomery, K. Raghavachari, M. A. Al-Laham, V. G. Zakrzewski, J. V. Ortiz, J. B. Foresman, J. Cioslowski, B. B. Stefanov, A. Nanayakkara, M. Challacombe, C. Y. Peng, P. Y. Ayala, W. Chen, M. W. Wong, J. L, Andres, E. S. Replogle, R. Gomperts, R. L. Martin, D. J. Fox, J. S. Binkley, D. J. Defrces, J. Baker, J. P. Stewart, M. Head-Gordon, C. Gonzalez, J. A. Pople,Gaussian 94, Revision D.1, Gaussian, Pittsburgh PA, 1995.

[64] F. Eckert, G. Rauhut, J. Am. Chem. Soc. 1998, 120, 13478.

[65] M. N. Glukhovtsev, R. D. Bach, A. Pross. L. Radom, Chem. Phys. Lett. 1996, 260, 558

[66] R. L. Bell, D. L. Tavacras, T. N. Truong, J. Simons, Int. J. Quantum Chem. 1997, 63.861. 
[67] P. v. R. Schleyer, C. Maerker, A. Dransfeld, H. Jiao, N. van Eikema Hommes, J. Am. Chem. Soc. 1996, $118,6317$.

[68] H. Jiao, P. von R. Schleycr, Angew. Chem. 1996, 108, 2548; Angew. Chem. Int. Ed. Engl. 1996, 35, 2383.

[69] R. W. F. Bader, Atoms in Molecules: A Quantum Theory, Oxford University Press, Oxford, 1990.
[70] J. M. Guest, J.S. Craw, M. A. Vincent, I. H. Hillier, J. Chem. Soc. Perkin Trans. 2 1997, 71.

[71] R. Arnaud, V. Dillet, N. Pelloux-Leon, Y. Vallec, J. Chem, Soc. Perkin Trans. 2 1996, 2065.

[72] R. Arnaud, Y. Vallee, J. Chem. Søc. Perkin Trans. 2 1997, 2737. 